\title{
Population Structure, Fungicide Resistance Profile, and sdhB Mutation Frequency of Botrytis cinerea from Strawberry and Greenhouse-Grown Tomato in Greece
}

Sotirios Konstantinou and Thomas Veloukas, Laboratory of Plant Pathology, School of Agriculture, Aristotle University of Thessaloniki (AUTH), POB 269, Thessaloniki, 511 24, Greece; Michaela Leroch, Plant Pathology Group, Department of Biology, University of Kaiserslautern, Kaiserslautern, Germany; George Menexes, Laboratory of Agronomy, School of Agriculture, AUTH; Matthias Hahn, Plant Pathology Group, Department of Biology, University of Kaiserslautern; and George Karaoglanidis, Laboratory of Plant Pathology, School of Agriculture, AUTH

\begin{abstract}
Konstantinou, S., Veloukas, T., Leroch, M., Menexes, G., Hahn, M., and Karaoglanidis, G. 2015. Population structure, fungicide resistance profile, and $s d h B$ mutation frequency of Botrytis cinerea from strawberry and greenhouse-grown tomato in Greece. Plant Dis. 99:240-248.

Botrytis cinerea is a pathogen with high genetic variability that has also shown high risk for fungicide resistance development. In total, 1,169 isolates obtained from strawberry $(n=297)$ and tomato $(n=872)$ in five geographic regions of Greece were tested for their sensitivity to several botryticides. A high frequency of isolates with multiple resistance to carbendazim, cyprodinil, pyraclostrobin, and boscalid was found in isolates from strawberry. In the isolates from tomato, the predominant phenotype was that of dual resistance to carbendazim and cyprodinil in the Crete island, of single resistance to carbendazim in the region of Preveza, and of sensitive isolates in the region of Kyparissia. None of the tested isolates was found to be fludioxonil resistant. High frequencies of boscalid-resistant phenotypes were observed in the strawberry isolates, while boscalid-resistance frequency in the tomato

isolates was lower. H272R was the predominant $s d h \mathrm{~B}$ mutation, associated with resistance to boscalid, in all the sampled isolates, while other $s d h B$ mutations were found at low frequencies. B. cinerea group $S$, identified by the presence of a 21-bp insertion in the transcription factor $m r r 1$ gene, was predominant within the tomato isolates obtained from all three sampled regions, with frequencies ranging from 62 to $75 \%$ of the isolates; whereas, within strawberry isolates, B. cinerea was predominant, with frequencies of 75 to $95 \%$. Correlations of isolate genotype and fungicide resistance profile showed that $B$. cinerea sensu stricto isolates were more prone to the development of resistance to boscalid compared with the Botrytis group $\mathrm{S}$ isolates, which may explain the observed predominance of $B$. cinerea sensu stricto in strawberry fields.
\end{abstract}

Botrytis cinerea Pers. is a ubiquitous fungus attacking more than 200 plant species in the temperate regions worldwide. It is a necrotrophic plant pathogen and causes a disease known as gray mold. All aboveground plant organs, including flowers, leaves, shoots, and fruit, are susceptible to $B$. cinerea (7).

$B$. cinerea is a heterogeneous fungal species. The main sources of its genetic variability include (i) heterokaryosis and the parasexual cycle, (ii) sexual reproduction, and (iii) mobile transposable elements (5). Until the end of the 1990s decade, B. cinerea was considered to be a single generalist species. However, identification of two transposable elements, Boty and Flipper, within the fungal genome led to a grouping based on the presence or absence of these transposable elements (15). Later on, the fungus was clustered in two different groups, group I and group II, based on DNA polymorphisms revealed by microsatellite markers and the level of sensitivity to the hydroxyanilide fungicide fenhexamid $(11,12)$. Recently, Botrytis group I was established as a new fungal species called B. pseudocinerea based on gene genealogy and sexual compatibility studies (39). Even more recently, Leroch et al. (23) provided evidence for the existence of a major $B$. cinerea subpopulation, provisionally called $B$. cinerea group $S$. The differentiation of $B$. cinerea sensu stricto and group $\mathrm{S}$ was based on differences of intergenic spacer restriction fragment length polymorphism patterns, sequence diversity in several genes, and host preferences (23).

The control of gray mold relies mainly on the use of fungicides with site-specific modes of action that belong to several chemical

Corresponding author: George Karaoglanidis, E-mail: gkarao@agro.auth.gr Accepted for publication 5 August 2014.

http://dx.doi.org/10.1094/PDIS-04-14-0373-RE

(C) 2015 The American Phytopathological Society classes such as benzimidazoles (MBCs), dicarboximides (DICs), hydroxyanilides (Hyds), anilinopyrimidines (APs), phenylpyrroles (PPs), and succinate dehydrogenase inhibitors (SDHIs) that represent the latest addition to the group of botryticides. In addition to them, quinone outside inhibitors (QoIs) show a suppressive action against gray mold and pyraclostrobin is used against the disease as a partner of the SDHI boscalid in a prepacked mixture. Multisite inhibitors such as chlorothalonil, dichlofluanid, iminactodine, and captan are used only in tank mixtures or in rotation with site-specific inhibitors because their efficacy in single applications is relatively low. However, B. cinerea is a classical "high-risk" pathogen and development of resistance to most fungicide classes has been reported worldwide (24). Resistance of B. cinerea to fungicides is commonly associated with target-site modifications conferring moderate or high levels of resistance. A G143A mutation in the cytochrome $b$ gene is associated with resistance to QoIs $(25,33)$, several mutations in the osmosensing histidine kinase (Bcbos1) are associated with resistance to DICs $(16,27)$, mutations in the 3-keto reductase gene $\operatorname{erg} 27$ are associated with resistance to Hyds $(10,17)$, and several mutations in the succinate dehydrogenase $B$ subunit $(s d h B)$ gene are associated with resistance to SDHIs $(25,37)$. Furthermore, low to moderate levels of resistance to several groups of botryticides have been reported in isolates from vineyards of Germany and France and strawberry fields in Germany and the United States to be associated with overexpression of efflux transporters $(20,26,30)$. Early $B$. cinerea resistance studies reported cases of resistance development to one single chemical class. However, in the recent past, the number of reports of multiple resistance to different chemical classes associated with the accumulation of different target-site mutations in the same strains has dramatically increased worldwide, representing a major threat for the successful control of the disease $(1,4,6,23,41)$.

Greenhouse-grown tomato and strawberry cultivated in the field under high-height plastic tunnels represent two high-value crops in Greece that are heavily treated with botryticides. Until now, little 
was known about the genetic structure of the fungal populations from these hosts in Greece, while information about the fungicide resistance profile was restricted only to SDHI or QoI resistance in strawberry populations $(33,37)$. Therefore, a study was initiated to (i) investigate the fungicide resistance profile of Botrytis spp. populations from strawberry and greenhouse-grown tomato in Greece, (ii) determine the frequency of $s d h \mathrm{~B}$ mutations associated with resistance to the SDHI boscalid in the fungal populations, and (iii) investigate the gray mold population composition in terms of $B$. cinerea sensu stricto and $B$. cinerea group $\mathrm{S}$ frequency within the collected populations.

\section{Materials and Methods}

Pathogen isolation and fungicide spray application history in the sampled sites. $B$. cinerea was isolated from diseased tomato fruit grown in greenhouses and strawberry fruit grown in plasticulture high-height plastic tunnels. Sampling for tomato isolates was conducted in three geographically distinct regions of Greece (Preveza, Kyparissia, and Crete island), while sampling for strawberry isolates was conducted in strawberry fields located in two regions of the country (Manolada and Pieria regions) (Fig. 1). Details related to the number of sampled greenhouses or fields and the total number of isolates obtained are given in Table 1 .

The sampling of the isolates from both hosts was conducted after the end of the spraying period during spring 2012. In all five sampled regions, fungicides belonging to the classes of QoIs, SDHIs, APs, PPs, and DICs had been used in alternation schemes (Table 1). The Hyd fenhexamid and the MBC thiophanate-methyl had been only rarely used in some fields of the Pieria or Preveza region. Strawberry fields in the region of Manolada were the most

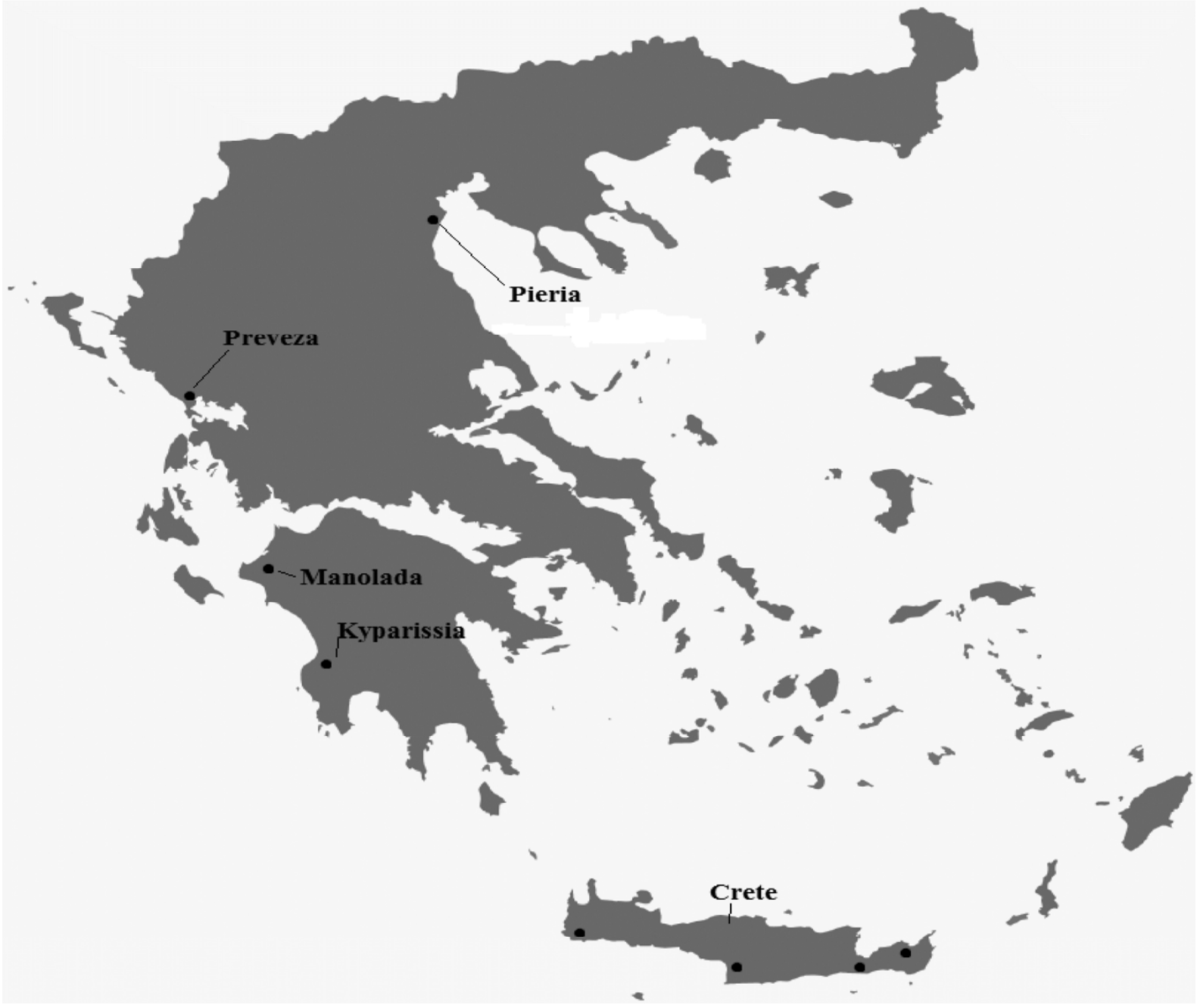

Fig. 1. Map of Greece showing the five Botrytis cinerea isolate sampling sites. Strawberry fields were sampled in the regions of Pieria $(n=122)$ and Manolada $(n=174)$ and tomato greenhouses were sampled in the regions of Preveza $(n=237)$, Kyparissia $(n=175)$, and Crete $(n=461)$.

Table 1. Botryticide spray application history during the 2011-12 spraying period in sampled strawberry and tomato fields

\begin{tabular}{|c|c|c|c|c|c|c|c|c|c|}
\hline \multirow[b]{2}{*}{ Host } & \multirow[b]{2}{*}{ Region } & \multicolumn{2}{|l|}{ Number of } & \multicolumn{6}{|c|}{ Number of botryticide spray applications ${ }^{\mathrm{z}}$} \\
\hline & & Fields or greenhouses & Isolates & Total & SDHIs, QoIs & APs, PPs & Hyd & MBCs & DICs \\
\hline Strawberry & Manolada & 8 & 175 & $2-9(7.2)$ & $2-5(4.0)$ & $1-4(2.7)$ & 0 & 0 & $0-2(0.5)$ \\
\hline Strawberry & Pieria & 6 & 122 & $5-8(6.5)$ & $2-4(2.9)$ & $0-3(2.1)$ & $0-3(1.4)$ & 0 & $0-2(0.4)$ \\
\hline Tomato & Crete & 25 & 461 & $0-8(4.2)$ & $0-2(0.7)$ & $0-6(2.3)$ & 0 & 0 & $0-3(1.2)$ \\
\hline Tomato & Kyparissia & 15 & 174 & $3-4(3.2)$ & $1-3(1.8)$ & $0-2(1.1)$ & 0 & 0 & $0-1(0.3)$ \\
\hline Tomato & Preveza & 11 & 237 & $5-11(7.9)$ & $0-3(2.0)$ & $2-6(4.3)$ & $0-2(0.6)$ & $0-2(0.4)$ & $0-3(1.0)$ \\
\hline
\end{tabular}

${ }^{2}$ SDHIs $=$ succinate dehydrogenase inhibitors (boscalid), QoIs $=$ quinone outside inhibitors (pyraclostrobin), APs $=$ anilinopyrimidines $($ cyprodinil or pyrimethanil), PPs = phenylpyrroles (fludioxonil), Hyd = hydroxyanilide (fenhexamid), MBCs = benzimidazoles (thiophanate-methyl), and DICs = dicarboxamides (iprodione). Value in parentheses is the mean number of botryticide applications in each sampled region. 
heavily treated fields, with the prepacked mixture of boscalid (SDHIs) and pyraclostrobin (QoIs) (Signum; BASF Hellas, Athens, Greece), while the mixture of cyprodinil (APs) and fludioxonil (PPs), (Switch; Syngenta Hellas, Athens, Greece) was the most commonly used fungicide in tomato greenhouses in the regions of Crete and Preveza (Table 1).

All isolates were collected from infected fruit showing abundant sporulation on the rotten fruit surface. Fungal spores were obtained from the sporulating lesions using sterile cotton swabs and then transferred to acidified potato dextrose agar (APDA) medium (lactic acid at $0.5 \mathrm{ml} / \mathrm{liter}[\mathrm{vol} / \mathrm{vol}])$ to suppress bacteria. Single fragments of actively growing mycelium, observed under the microscope, were transferred from APDA plates onto fresh PDA plates and incubated at $20^{\circ} \mathrm{C}$, in the dark for 1 week. The cultures were maintained at $4^{\circ} \mathrm{C}$ until use.

DNA isolation and species or group identification. To extract DNA, the isolates were grown in potato dextrose broth (SigmaAldrich, St. Louis) for 3 days at $22^{\circ} \mathrm{C}$. Mycelium was harvested by filtration, dried, lyophilized, ground to a fine powder using micropestles (Eppendorf International, Wesseling, Germany), and stored at $-20^{\circ} \mathrm{C}$ until use. DNA was extracted using QIA Puregene Core Kit A (Qiagen GmbH, Hilden, Germany) according to the manufacturer's protocol. The concentration of extracted DNA was measured using a P330 nanophotometer (Implen GmbH, Munich, Germany).

Differentiation of gray mold isolates to $B$. cinerea sensu stricto and $B$. cinerea group $S$ was based on a polymerase chain reaction (PCR) assay developed by Leroch et al. (23). The primer pair mrr1_spez_F (TATCGGTCTTGCAGTCCGC) and mrr1_spez_R (TTCCGTACCCCGATCTTCGGAA) was used to detect a 21-bp insertion in the $m r r l$ gene characterizing $B$. cinerea group $\mathrm{S}$ isolates but not $B$. cinerea sensu stricto. PCR reaction reagents and the amplification protocol were as described by Leroch et al. (23). PCR reaction mixtures were incubated in a PTC 200 thermal cycler (MJ Research, Waltham, MA) and the PCR products were size verified in $1.5 \%$ agarose gels in Tris-borate-EDTA buffer, supplemented with ethidium bromide $(0.1 \mu \mathrm{g} / \mathrm{ml})$ by electrophoresis, and viewed under UV light.

Fungicide resistance profile determination. The fungicide resistance phenotype of the collected isolates was determined using discriminatory concentrations of the MBC carbendazim (Pacarzim 50WP; Papaoikonomou Agrochemicals S.A.), the AP cyprodinil (Chorus 50WG; Syngenta Hellas), the PP fludioxonil (Geoxe 50WG; Syngenta Hellas), the Hyd fenhexamid (Teldor 50 WG; Bayer Hellas), the QoI pyraclostrobin (BAS 500 06F 20EC; BASF Hellas), and the SDHI boscalid (Cantus 50WG; BASF Hellas). Conidial suspensions for each isolate were prepared in sterile water $\left(2 \times 10^{5}\right.$ conidia/ml $)$.

To determine isolates' sensitivity to carbendazim, fludioxonil, cyprodinil, and fenhexamid, a previously developed protocol was used $(22,23)$. The conidial suspension $(20 \mu \mathrm{l})$ was transferred to hydroxyapatite (HA) medium (4 $\mathrm{g}$ of yeast extract, $4 \mathrm{~g}$ of glucose, $10 \mathrm{~g}$ of malt extract, and $15 \mathrm{~g}$ of agar per liter of medium; 23), amended with carbendazim, fludioxonil, and fenhexamid at 5, 0.8, and $3 \mu \mathrm{g} / \mathrm{ml}$, respectively; or on Gamborg B5 medium (3 $\mathrm{g}$ of Gamborg, $1.36 \mathrm{~g}$ of $\mathrm{KH}_{2} \mathrm{PO}_{4}, 9.9 \mathrm{~g}$ of glucose, and $15 \mathrm{~g}$ of agar per liter of medium, $\mathrm{pH} 5.5 ; 20$ ), amended with cyprodinil at $8 \mu \mathrm{g} / \mathrm{ml}$. After $72 \mathrm{~h}$ of incubation at $20^{\circ} \mathrm{C}$ in the dark, the cultures were visually checked for the presence or absence of mycelial growth. Isolates showing visible mycelial colony growth where the conidial suspension was applied were considered fungicide-resistant.

To determine the sensitivity to pyraclostrobin and boscalid, $40 \mu \mathrm{l}$ of the conidial suspensions were spread on $2 \%$ water agar media (+salicylhydroxamic acid at $100 \mu \mathrm{g} / \mathrm{ml}$ ) or yeast-bacto-acetate agar medium (10 g of yeast extract, $10 \mathrm{~g}$ of Bacto peptone, $20 \mathrm{~g}$ of sodium acetate, and $15 \mathrm{~g}$ of agar per liter of medium), amended with pyraclostrobin at $5 \mu \mathrm{g} / \mathrm{ml}$ or boscalid at $2 \mu \mathrm{g} / \mathrm{ml}$, respectively. At these concentrations, conidial germination of pyraclostrobin- or boscalid-sensitive isolates is fully inhibited, as shown in previous studies by our group $(33,38)$. After $20 \mathrm{~h}$ of incubation at $20^{\circ} \mathrm{C}$ in the dark, conidia were examined microscopically for germination. Isolates were classified as either sensitive or resistant based on the presence or absence of conidial germination. A conidium was considered germinated if the germ tube was at least twice the length of the conidium.

Identification of $s d h \mathrm{~B}$ mutations. The identification of $s d h \mathrm{~B}$ mutations was conducted on isolates that were found to be resistant to boscalid, using a primer introduced restriction analysis (PIRA)PCR technique developed previously (37). The technique was able to identify five different $s d h \mathrm{~B}$ mutations $(\mathrm{H} 272 \mathrm{~L},-\mathrm{R}$, and $-\mathrm{Y}$;

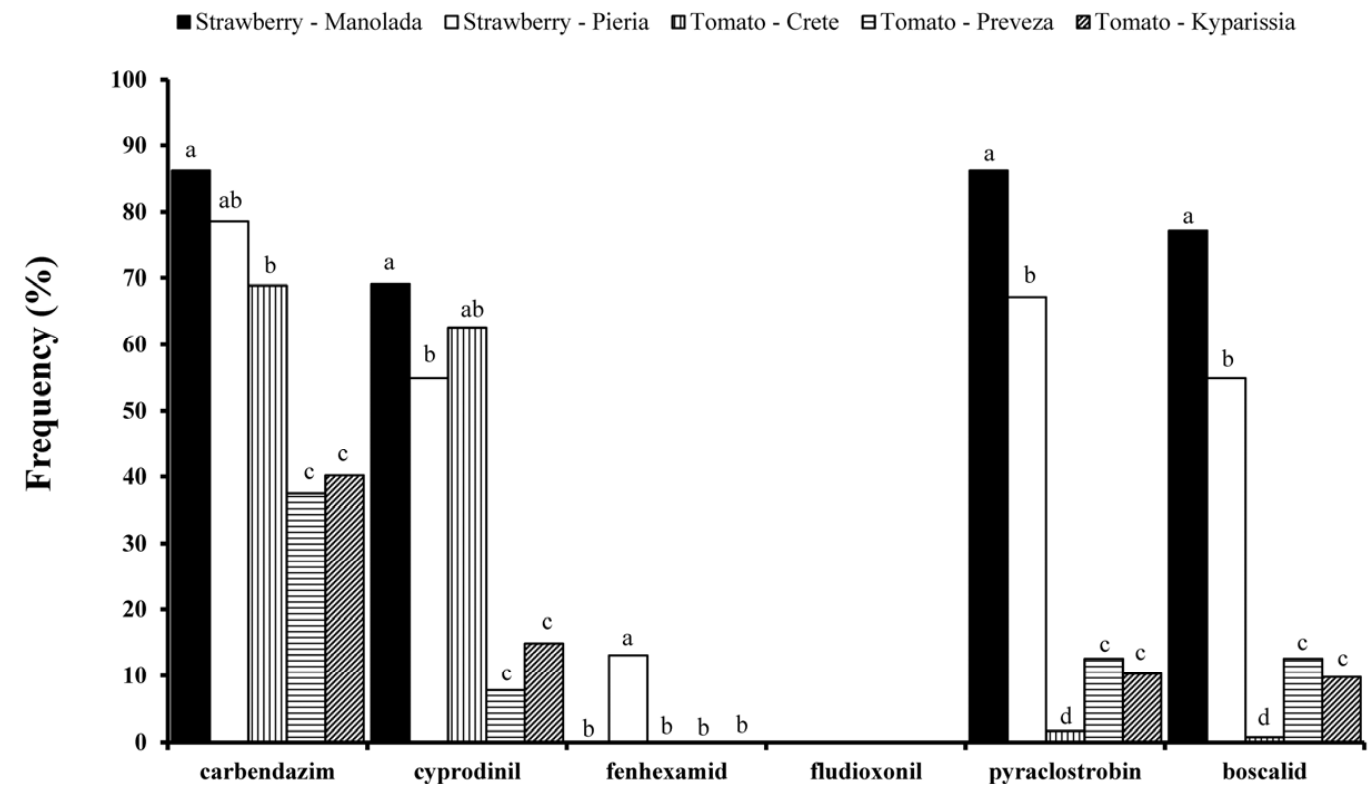

Fungicides

Fig. 2. Frequencies (\%) of resistance to fungicides of different chemical classes in Botrytis cinerea populations obtained from strawberry fields and tomato greenhouses in five different regions of Greece. Isolates considered sensitive were susceptible to all the tested fungicides. For each resistance phenotype, different letters on the columns indicate significant differences in frequencies between subpopulations from the different sampled regions, according to $\chi^{2}$ analysis followed by a series of $z$ tests at $\alpha=0.05$. 
P225F; and N230I) associated with resistance to boscalid. For this purpose, specific mismatched primer pairs were used for each mutation (37). Mismatches were selected to artificially create HindIII, BamHI, BglII, HhaI, and EcoRV restriction sites during PCR to detect P225F, N230I, H272L, H272R, and H272Y mutations, respectively.

Data analysis. Data were recorded as frequencies (percentages) of resistant isolates. The $\chi^{2}$ test was used for comparing frequency distributions between groups of data. Proportions were compared with the $\mathrm{z}$ test. In all hypothesis testing procedures, the observed significance level ( $\alpha$ value) was computed with the Monte-Carlo simulation method (29), utilizing 10,000 resampling cycles. This method leads to valid inferential conclusions even in cases where the methodological presuppositions of the corresponding statistical tests are not fulfilled. The significance level of all hypothesis testing procedures was predetermined at $\alpha=0.05$. Statistical analyses were accomplished by the SPSS software (v.20.0; Armonk, NY) enhanced with the module Exact Tests (for Monte-Carlo implementation).

\section{Results}

Fungicide resistance frequencies. Among isolates from both crops, resistance to carbendazim (MBCs) was the most common resistance, with frequencies of 78.6 to $86.2 \%$ and 37.5 to $68.9 \%$ in the strawberry and tomato populations, respectively (Fig. 2). Similarly, high frequencies of resistance were observed to the QoI pyraclostrobin (67.2 to 86.2\%) and the SDHI boscalid (54.9 to $77.1 \%$ ) in strawberry populations. In contrast, in the tomato populations, resistance frequencies to pyraclostrobin and boscalid were lower $(P<0.05)$ compared with that in strawberry populations. Interestingly, in Crete island, only four isolates $(0.8 \%)$ were found to be resistant to boscalid (Fig. 2). In the remaining two regions from which tomato populations were sampled, Kyparissia and Preveza, resistance frequencies to both fungicides ranged around 10\%. High frequencies of resistance were also found to cyprodinil (APs) in both crops, ranging from 54.9 to $69.1 \%$ and 7.8 to $62.6 \%$ in the strawberry and tomato populations, respectively (Fig. 2). Resistance to the Hyd fungicide fenhexamid was found to occur only in the fungal population obtained from strawberry fields in the region of Pieria at a frequency of $13.1 \%$, while resistance to the PP fungicide fludioxonil was not observed in any of the populations tested (Fig. 2).

In both hosts, frequencies of resistance to boscalid were found to be correlated with the total number of boscalid treatments applied prior to the sampling of the isolates. For example, in strawberry fields located in Manolada, the boscalid resistance frequency was found to be only $15.3 \%$ in a field treated twice with boscalid, whereas higher $(P<0.05)$ frequencies of $85.6,93.5$, or $95,6 \%$ were observed in fields treated with boscalid in three, four, or five spray applications, respectively (Table 2). The same pattern was also observed in tomato greenhouses located in the regions of Kyparissia and Preveza, in which a stepwise increase in the boscalid resistance frequency was observed in greenhouses that received a high number of boscalid spray applications (Table 2). In contrast, the frequencies of resistance to cyprodinil or carbendazim were not correlated with the number of APs or MBCs treatments applied prior to the sampling of isolates (data not shown).

Multiple fungicide resistance phenotypes. Marked differences were observed between the populations from the two sampled hosts regarding the accumulation of specific resistances in the same isolate (multiple fungicide resistance). In the isolates obtained from strawberry, simultaneous resistance to four different chemical classes (R4) was the most common phenotype (57.2 and $35.2 \%$ ) in the regions of Manolada and Pieria, respectively (Table 3). High frequencies of triple resistance (R3: 22.4 and 24.6\%) were also observed in the regions of Manolada and Pieria, respectively. In contrast, in the isolates obtained from tomato, the R3 and R4 phenotypes were observed in relatively low frequencies. In Crete, resistance to two different chemical classes was the more common phenotype (R2) observed at a frequency of $49.6 \%$ whereas, in the remaining two regions in which tomato greenhouses had been sampled, Kyparissia and Preveza, the most common resistance phenotype was that of resistance to a single chemical class (R1: 28.6 and $59.9 \%$, respectively; Table 3 ).

In total, 17 distinct resistance phenotypes were observed, 15 of them in isolates from strawberry and 12 in isolates from tomato

Table 2. Boscalid resistance frequency (\%) of Botrytis cinerea populations from strawberry and tomato fields treated with different numbers of boscalid applications during the $2011-12$ cropping season ${ }^{y}$

\begin{tabular}{llcccccc}
\hline & & \multicolumn{5}{c}{ Resistance frequency $(\boldsymbol{\%})$ per number of boscalid applications } \\
\cline { 3 - 7 } Region & Host & $\mathbf{0}$ & $\mathbf{1}$ & $\mathbf{2}$ & $\mathbf{3}$ & $\mathbf{4}$ & $\mathbf{5}$ \\
\hline Manolada & Strawberry & - & - & $15.3 \mathrm{a}$ & $85.6 \mathrm{~b}$ & $93.5 \mathrm{bc}$ & $95.6 \mathrm{c}$ \\
Pieria & Strawberry & - & - & $35.7 \mathrm{a}$ & $52.5 \mathrm{~b}$ & - & $-32.3 \mathrm{c}$ \\
Crete & Tomato & 0.8 & 1.1 & 0.0 & - & - & - \\
Kyparissia & Tomato & - & $3.0 \mathrm{a}$ & $3.2 \mathrm{a}$ & $48.0 \mathrm{~b}$ & - & - \\
Preveza & Tomato & $0.0 \mathrm{a}$ & $0.0 \mathrm{a}$ & $14.5 \mathrm{~b}$ & $21.6 \mathrm{c}$ & - \\
\hline
\end{tabular}

${ }^{y}$ Frequency of resistance to boscalid was determined based on the inhibition of spore germination on yeast-bacto-acetate agar medium amended with boscalid at $2 \mu \mathrm{g} / \mathrm{ml}$.

${ }^{\mathrm{z}}$ Different letters in the rows indicate significant differences in resistance frequency $(\%)$ values among fields or greenhouses that received different numbers of boscalid applications according to a series of $\mathrm{z}$ tests at $\alpha=0.05$; - indicates absence of fields or greenhouses treated with the indicated number of fungicide applications.

Table 3. Frequencies (\%) of multiple resistance to fungicides of different chemical classes in Botrytis cinerea isolates obtained from strawberry and greenhouse-grown tomato in five different regions of Greece ${ }^{\mathrm{y}}$

\begin{tabular}{|c|c|c|c|c|c|}
\hline \multirow[b]{2}{*}{ Resistances $^{\mathrm{Z}}$} & \multicolumn{2}{|c|}{ Strawberry } & \multicolumn{3}{|c|}{ Tomato } \\
\hline & Manolada & Pieria & Crete & Preveza & Kyparissia \\
\hline R0 & $3.2 \mathrm{c}$ & $13.9 \mathrm{~b}$ & $17.1 \mathrm{~b}$ & $19.4 \mathrm{~b}$ & $52.8 \mathrm{a}$ \\
\hline R1 & $6.7 \mathrm{c}$ & $11.4 \mathrm{c}$ & $31.8 \mathrm{~b}$ & $59.9 \mathrm{a}$ & $28.6 \mathrm{~b}$ \\
\hline R2 & $10.3 \mathrm{~b}$ & $9.7 \mathrm{~b}$ & $49.6 \mathrm{a}$ & $8.9 \mathrm{~b}$ & $8.6 \mathrm{~b}$ \\
\hline R3 & $22.4 \mathrm{a}$ & $24.6 \mathrm{a}$ & $0.2 \mathrm{c}$ & $7.5 \mathrm{~b}$ & $9.8 \mathrm{~b}$ \\
\hline R4 & $57.2 \mathrm{a}$ & $35.2 \mathrm{~b}$ & $0.4 \mathrm{~d}$ & $3.8 \mathrm{c}$ & $0.0 \mathrm{~d}$ \\
\hline R5 & $0.0 \mathrm{~b}$ & $4.9 \mathrm{a}$ & $0.0 \mathrm{~b}$ & $0.0 \mathrm{~b}$ & $0.0 \mathrm{~b}$ \\
\hline
\end{tabular}

${ }^{y}$ Different letters in the rows indicate significant differences in phenotype frequencies (\%) among the different regions according to $\chi^{2}$ test followed by a series of $\mathrm{z}$ tests at $\alpha=0.05$.

${ }^{\mathrm{z}}$ Number of accumulated resistances: $\mathrm{R} 0=$ isolates sensitive to all the fungicides tested; R1, R2, R3, R4, and R5 = isolates with resistance to one, two three, four, or five, different chemical classes. 
(Table 4). In both strawberry populations, the most common phenotype was that of quadruple resistance to boscalid, pyraclostrobin, carbendazim, and cyprodinil (57.2 and 30.3\%) in Manolada and Pieria, respectively (Table 4). Furthermore, in the region of Pieria, a small fraction of the population showed simultaneous resistance to five different fungicides (boscalid, pyraclostrobin, carbendazim, cyprodinil, and fenhexamid) at a frequency of $4.9 \%$ (Table 4 ). In the population obtained from tomato greenhouses in the region of Crete, the most common phenotype was that of dual resistance to carbendazim and cyprodinil $(48.8 \%)$, while single resistance to carbendazim was the most common resistance phenotype in the populations obtained from the regions of Kyparissia and Preveza (21.8 and $57.4 \%$, respectively; Table 4).

Frequency of $\boldsymbol{s d h} \mathbf{B}$ mutations. All boscalid-resistant isolates were screened using the PIRA-PCR technique to identify the mutations associated with resistance to SDHIs. In total, five different $s d h \mathrm{~B}$ mutations (P225F, N230I, and H272R, -Y, and -L), were identified. H272R was by far the predominant mutation associated with resistance to boscalid in all populations sampled, with frequencies of 93.5, 68.4, 100, 94.1, and 83.3\% in the isolates from Manolada, Pieria, Crete, Kyparissia, and Preveza, respectively (Table 5). The H272Y mutation was found at frequencies of 5.1 and $15.2 \%$ in the two strawberry populations sampled and at a frequency of $16.7 \%$ in the tomato population obtained from the region of Preveza. The N230I mutation was detected in the two strawberry populations sampled $(0.7$ and $8.4 \%$ in the regions of Manolada and Pieria, respectively), and in the tomato population obtained from the region of Kyparissia (Table 5). Mutations H272L and P225F were rarely found and were observed only in isolates obtained from strawberry fields (Table 5).

Population structure. PCR-based identification of $B$. cinerea sensu stricto and $B$. cinerea group $S$ revealed the widespread presence of both groups. In both populations obtained from strawberry, $B$. cinerea sensu stricto was the most prevalent genotype, with frequencies of 78.9 to $94.1 \%$ (Fig. 3). In contrast, in all three populations from tomato, group $\mathrm{S}$ was found to be the predominant genotype, with frequencies of $74.5,71.0$, and $58.9 \%$ in the regions of Crete, Preveza, and Kyparissia, respectively (Fig. 3).

In the populations obtained from tomato, the frequency of resistance to cyprodinil and carbendazim was higher $(P<0.05)$ within the group of $B$. cinerea group $\mathrm{S}$ isolates. For example, 71.5 and $53.6 \%$ of the group $S$ isolates were resistant to carbendazim and cyprodinil, while only 38.2 and $25 \%$ of the B. cinerea sensu stricto isolates were resistant to carbendazim and cyprodinil, respectively (Fig. 4A). In contrast, only $4.8 \%$ of the $B$. cinerea group $\mathrm{S}$ isolates obtained from tomato were resistant to either pyraclostrobin or boscalid, while 29.4 and $25 \%$ of the $B$. cinerea sensu stricto isolates were resistant to these fungicides, respectively (Fig. 4A). Similarly, in the populations obtained from strawberry fields, only 8.6 and $4.3 \%$ of the group $S$ isolates were pyraclostrobin or boscalid resistant, respectively. However, higher $(P<0.05)$ resistance frequencies were observed within the $B$. cinerea sensu stricto subpopulation, with values of 88.2 and $81.6 \%$, respectively (Fig. 4B). Within the B. cinerea sensu stricto subpopulations from strawberry were also observed higher frequencies of resistance to carbendazim and cyprodinil compared with that observed within

Table 4. Frequency (\%) of single or multiple resistance to specific fungicide in different classes in Botrytis cinerea populations obtained from strawberry and greenhouse-grown tomato fields

\begin{tabular}{|c|c|c|c|c|c|}
\hline \multirow[b]{3}{*}{ Resistance phenotype $^{z}$} & \multicolumn{5}{|c|}{ Host $^{y}$} \\
\hline & \multicolumn{2}{|c|}{ Strawberry } & \multicolumn{3}{|c|}{ Tomato } \\
\hline & Manolada & Pieria & Crete & Kyparissia & Preveza \\
\hline Sensitive & $3.4 \mathrm{bcd}$ & $14.0 \mathrm{~b}$ & $18.0 \mathrm{~b}$ & $52.9 \mathrm{a}$ & $19.8 \mathrm{~b}$ \\
\hline $\mathrm{Carb}^{\mathrm{R}}$ & $5.0 \mathrm{bc}$ & $7.3 \mathrm{bc}$ & $18.2 \mathrm{~b}$ & $21.8 \mathrm{~b}$ & $57.4 \mathrm{a}$ \\
\hline Cypro $^{R}$ & $0.6 \mathrm{de}$ & $3.2 \mathrm{~cd}$ & $13.2 \mathrm{~b}$ & $6.9 \mathrm{c}$ & $2.5 \mathrm{cde}$ \\
\hline Pyra $^{R}$ & $1.1 \mathrm{cde}$ & $0.0 \mathrm{e}$ & $0.4 \mathrm{c}$ & $0.0 \mathrm{~d}$ & $0.0 \mathrm{f}$ \\
\hline $\mathrm{Fen}^{\mathrm{R}}$ & $0.0 \mathrm{e}$ & $0.9 \mathrm{de}$ & $0.0 \mathrm{c}$ & $0.0 \mathrm{~d}$ & $0.0 \mathrm{f}$ \\
\hline Carb $^{R}$ Cypro $^{R}$ & $4.6 \mathrm{bc}$ & $4.9 \mathrm{~cd}$ & $48.8 \mathrm{a}$ & $8.0 \mathrm{c}$ & $5.9 \mathrm{c}$ \\
\hline $\mathrm{Carb}^{\mathrm{R}} \mathrm{Fen}^{\mathrm{R}}$ & $0.0 \mathrm{e}$ & $2.4 \mathrm{cde}$ & $0.0 \mathrm{c}$ & $0.0 \mathrm{~d}$ & $0.0 \mathrm{f}$ \\
\hline $\mathrm{Pyra}^{\mathrm{R}} \mathrm{Carb}^{\mathrm{R}}$ & $3.4 \mathrm{bcd}$ & $0.0 \mathrm{e}$ & $0.6 \mathrm{c}$ & $0.6 \mathrm{~d}$ & $1.3 \mathrm{def}$ \\
\hline Pyra $^{R}$ Cypro $^{R}$ & 1.7 cde & $0.0 \mathrm{e}$ & $0.0 \mathrm{c}$ & $0.0 \mathrm{~d}$ & $0.0 \mathrm{f}$ \\
\hline $\operatorname{Bosc}^{\mathrm{R}} \mathrm{Carb}^{\mathrm{R}}$ & $0.0 \mathrm{e}$ & $0.0 \mathrm{e}$ & $0.2 \mathrm{c}$ & $0.0 \mathrm{~d}$ & $0.0 \mathrm{f}$ \\
\hline Bosc $^{R}$ Pyra $^{R}$ & $0.6 \mathrm{de}$ & 2.4 cde & $0.0 \mathrm{c}$ & $0.0 \mathrm{~d}$ & $1.3 \mathrm{def}$ \\
\hline $\mathrm{Bosc}^{\mathrm{R}} \mathrm{Cypro}^{\mathrm{R}}$ & $0.0 \mathrm{e}$ & $0.0 \mathrm{e}$ & $0.0 \mathrm{c}$ & $0.0 \mathrm{~d}$ & $0.4 \mathrm{ef}$ \\
\hline Pyra $^{\mathrm{R}}$ Carb $^{\mathrm{R}}$ Cypro $^{\mathrm{R}}$ & $3.4 \mathrm{bcd}$ & $12.3 \mathrm{~b}$ & $0.0 \mathrm{c}$ & $0.0 \mathrm{~d}$ & 0.4 ef \\
\hline $\operatorname{Bosc}^{\mathrm{R}} \mathrm{Pyra}^{\mathrm{R}} \mathrm{Carb}^{\mathrm{R}}$ & $13.2 \mathrm{~b}$ & $12.3 \mathrm{~b}$ & $0.2 \mathrm{c}$ & $9.8 \mathrm{c}$ & $5.0 \mathrm{~cd}$ \\
\hline Bosc $^{\mathrm{R}}$ Pyra $^{\mathrm{R}}$ Cypro $^{\mathrm{R}}$ & $5.8 \mathrm{c}$ & $0.0 \mathrm{e}$ & $0.0 \mathrm{c}$ & $0.0 \mathrm{~d}$ & $2.1 \mathrm{de}$ \\
\hline Bosc $^{R}$ Pyra $^{R}$ Carb $^{R}$ Cypro $^{R}$ & $57.2 \mathrm{a}$ & $30.3 \mathrm{a}$ & $0.4 \mathrm{c}$ & $0.0 \mathrm{~d}$ & $3.8 \mathrm{~cd}$ \\
\hline Bosc $^{R}$ Pyra $^{R} \operatorname{Carb}^{R}$ Fen $^{R}$ & $0.0 \mathrm{e}$ & $4.9 \mathrm{~cd}$ & $0.0 \mathrm{c}$ & $0.0 \mathrm{~d}$ & $0.0 \mathrm{f}$ \\
\hline Bosc $^{R}$ Pyra $^{R}$ Carb $^{R}$ Cypro $^{R}$ Fen $^{R}$ & $0.0 \mathrm{e}$ & $4.9 \mathrm{~cd}$ & $0.0 \mathrm{c}$ & $0.0 \mathrm{~d}$ & $0.0 \mathrm{f}$ \\
\hline
\end{tabular}

${ }^{\mathrm{y}}$ In each sampled region, different letters in the columns indicate significant differences in resistance phenotype frequencies according to a series of $\mathrm{z}$ tests at $\alpha=0.05$.

${ }^{\mathrm{z}}$ Resistant to: $\mathrm{Carb}^{\mathrm{R}}=$ carbendazim (benzimidazoles), Cypro $^{\mathrm{R}}=$ cyprodinil (anilinopyrimidines), $\mathrm{Pyra}^{\mathrm{R}}=$ pyraclostrobin (quinone outside inhibitors), Fen ${ }^{\mathrm{R}}=$ fenhexamid (hydroxyanilides), and $\mathrm{Bosc}^{\mathrm{R}}=$ boscalid (succinate dehydrogenase inhibitors).

Table 5. Frequency (\%) of different $s d h \mathrm{~B}$ mutants within the fraction of boscalid-resistant subpopulations of Botrytis cinerea collected from strawberry field and tomato greenhouses in five different regions of Greece

\begin{tabular}{|c|c|c|c|c|c|c|c|}
\hline \multirow[b]{2}{*}{ Region } & \multirow[b]{2}{*}{ Host } & \multirow[b]{2}{*}{ Number of isolates ${ }^{\mathrm{z}}$} & \multicolumn{5}{|c|}{ Frequency of isolates $(\%)$ per $s d h \mathrm{~B}$ mutation ${ }^{\mathrm{y}}$} \\
\hline & & & P225F & N230I & H272L & H272R & H272Y \\
\hline Manolada & Strawberry & 135 & 0.0 & 0.7 & 0.7 & 93.5 & 5.1 \\
\hline Pieria & Strawberry & 67 & 5.1 & 8.4 & 1.7 & 68.4 & 15.2 \\
\hline Crete & Tomato & 4 & 0.0 & 0.0 & 0.0 & 100 & 0.0 \\
\hline Kyparissia & Tomato & 17 & 0.0 & 5.9 & 0.0 & 94.1 & 0.0 \\
\hline Preveza & Tomato & 30 & 0.0 & 0.0 & 0.0 & 83.3 & 16.7 \\
\hline
\end{tabular}

${ }^{\mathrm{y}} s d h \mathrm{~B}$ mutations were detected using a primer introduced restriction analysis (PIRA) polymerase chain reaction technique (37).

${ }^{\mathrm{z}}$ Number of boscalid-resistant isolates in each region. 
the $B$. cinerea group S subpopulation, whereas resistance to fenhexamid was found to occur in equal frequencies (Fig. 4B).

\section{Discussion}

In the current study, the fungicide resistance profile and the structure of populations of the gray mold pathogen from strawberry and greenhouse-grown tomato in Greece were investigated.
Measurements of resistance frequencies to the most important and commonly used fungicides showed that multiple resistances have evolved. Resistance to MBCs was found to be the most common phenotype in fungal isolates obtained from both crops, despite the fact that MBCs are no longer commonly used against gray mold or other foliar diseases. This long persistence of high frequency of benzimidazole resistance, even in the absence of selection pres-

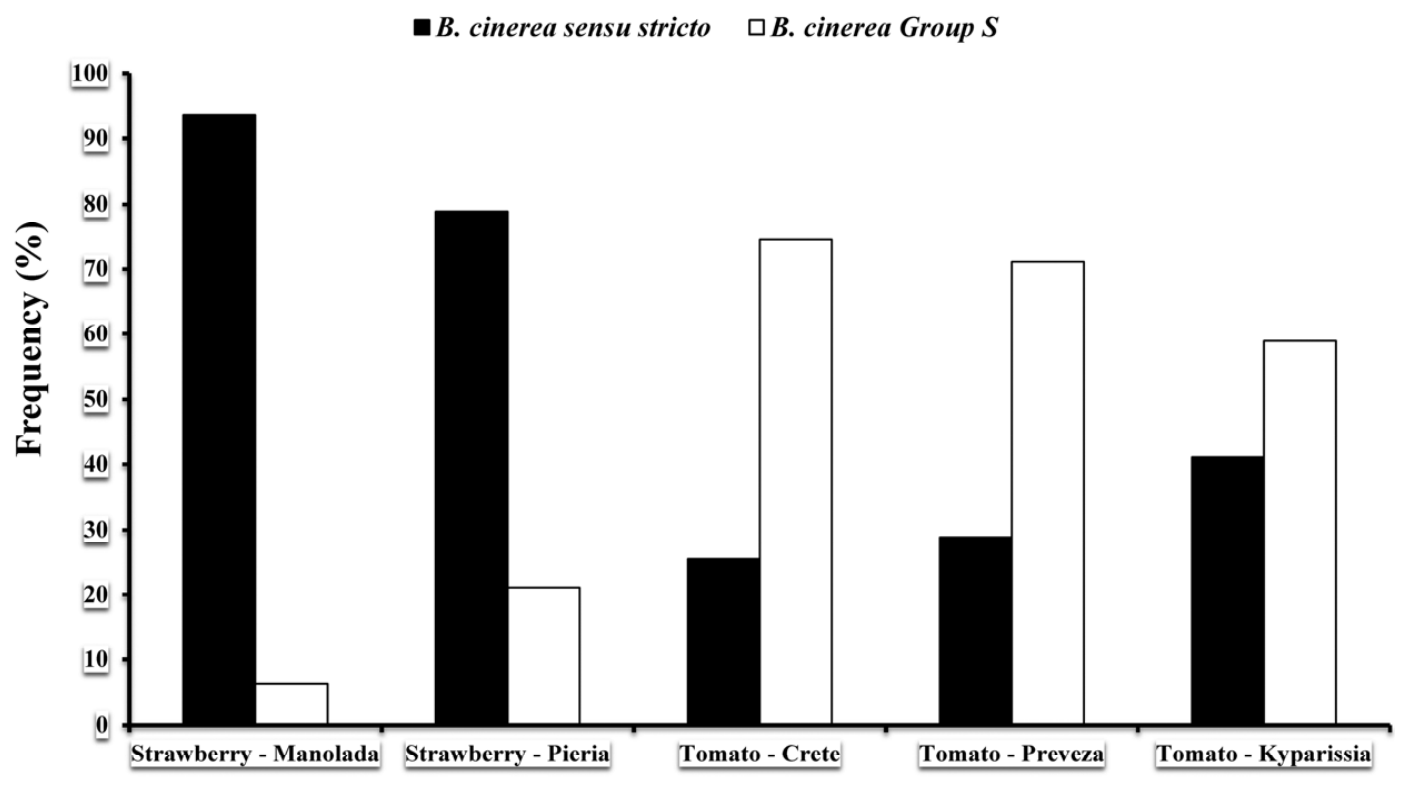

Host/Region

Fig. 3. Frequency (\%) of Botrytis cinerea and Botrytis "group S" strains within gray mold populations from strawberry fields in the regions of Manolada $(n=175)$ and Pieria $(n$ $=122)$ and tomato greenhouses in the regions of Preveza $(n=237)$, Kyparissia $(n=174)$, and Crete $(n=461)$ in Greece.

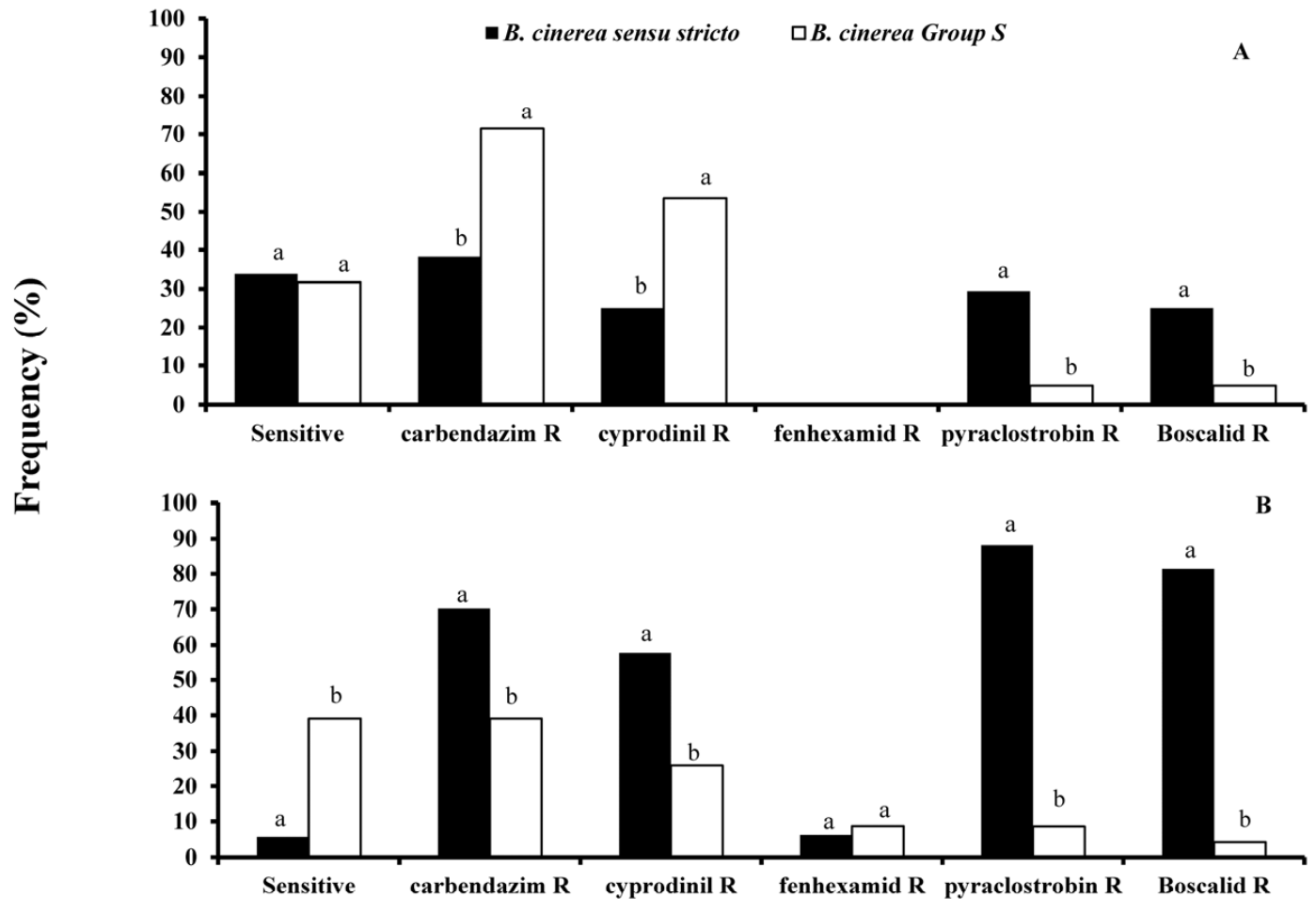

Fungicide Resistance Phenotype

Fig. 4. Frequency (\%) of fungicide resistant phenotypes within Botrytis cinerea sensu stricto and Botrytis group $\mathbf{S}$ isolates from $\mathbf{A}$, tomato and $\mathbf{B}$, strawberry fields collected from several regions of Greece. Different letters on the columns indicate statistically significant differences in phenotype frequencies (\%) within each fungicide resistance phenotype according to a series of $z$ tests at $\alpha=0.05$. 
sure, has been observed in other studies and is probably related to the high fitness of the benzimidazole-resistant strains $(23,32,43)$.

Boscalid was the first member of the SDHI group introduced against gray mold in 2007. However, cases of resistance development to this compound were soon reported in several countries, including Greece $(4,9,19,22,25,37)$. In the current study, resistance to boscalid was also found to occur at high frequencies in the two strawberry populations tested whereas, in the tomato populations, resistance to boscalid and QoIs was either almost absent or at low to moderate frequencies. However, in both crops, the observed frequencies were correlated with the total number of SDHI treatments applied before sampling. This is in agreement with previous findings suggesting that limitations in the number of SDHI treatments were effective in the management of $B$. cinerea resistance to SDHIs in French vineyards (40). Based on such findings, Fungicide Resistance Action Committee recommendations suggest a limited number of SDHI treatments in vegetable and small berry crops (13).

Resistance to SDHIs has been associated with several mutations located in $s d h \mathrm{~B}, s d h \mathrm{C}$, and $s d h \mathrm{D}$ subunits $(25,35,37,42)$. Despite the fact that there are already several reports on the frequency of $s d h$ mutations in boscalid-resistant fungal populations from strawberry or grape, currently there are no similar reports for $B$. cinerea populations from tomato. Precise knowledge of the frequency of specific mutations associated with resistance to SDHIs within fungal populations is of high importance for successful control of the disease or the implementation of appropriate antiresistance strategies. This is because it is well established that $s d h$ mutations differentially affect the sensitivity of the mutated $B$. cinerea strains to different molecules belonging to SDHIs $(2,21,34,38)$. Newer SDHI molecules such as fluopyram, fluxapyroxad, or penthiopyrad have been recently or will be introduced in the near future and integrated into the spray programs applied against the pathogen. In the case of previously selected $s d h$ mutants, the efficacy of these new products may be greatly affected by the type of $s d h$ mutations and their respective frequency within fungal populations. Furthermore, applications of these new SDHI molecules may contribute to the elimination of previously selected mutations or may favor the selection of novel mutations or contribute to the increase in frequency of mutations that already have been selected but occur at low frequencies. In the current report, we provided evidence on the prevalence of $\mathrm{H} 272 \mathrm{R}$ mutants within the boscalid-resistant fraction of the fungal populations obtained from strawberry and tomato. This mutation has been previously shown to be predominant in fungal populations from strawberry and apples in the United States $(2,9,42)$. Interestingly, mutations such as the P225F or the H272L associated with higher levels of resistance to boscalid compared with that conferred by $\mathrm{H} 272 \mathrm{R}$ mutations have been found in very low frequencies. The lower frequency of these mutants is probably correlated with a fitness cost that has been confirmed recently both for isogenic and field strains of the pathogen $(21,36)$.

Resistance to boscalid was, in most cases, found to be associated with resistance to pyraclostrobin. This finding is not unexpected because, until recently, the only available SDHI-containing product registered against gray mold was a prepacked mixture of boscalid with the QoI fungicide pyraclostrobin. Obviously, the exclusive use of this prepacked mixture co-selected for resistance to both fungicides classes. The slightly higher frequency of resistance to QoIs compared with that of boscalid suggests that resistance to QoIs developed earlier because other QoIs such as azoxystrobin were applied in strawberry fields or tomato greenhouses against other diseases such as powdery mildew or anthracnose in strawberry and powdery mildew or late blight in tomato. A similar occurrence of $B$. cinerea strains with simultaneous resistance to both classes of respiration inhibitors has also been observed in fungal populations from strawberry or apples in the United States $(9,19)$ and from grape in Germany and France $(23,25,41)$.

Resistance to cyprodinil was found to be very common in the isolates from strawberry and in the isolates obtained from tomato cultivated in Crete. APs were registered in Greece as botryticides in 1998 and have been used extensively since then. Two molecules are used in the country: pyrimethanil applied as a solo product and cyprodinil applied in prepacked mixture with the PP fludioxonil. Resistance to APs was detected in Greece for the first time in 2005, at a frequency of $49 \%$, during a monitoring conducted in vegetable crops of Crete island (31). Thus, the current study confirms a further increase of resistance frequency at $62.6 \%$. The observed high frequencies of resistance to APs are associated with increased selection pressure and the high fitness of AP-resistant strains (3).

Despite the widespread presence of resistance to cyprodinil in both hosts and in all the sampled regions, no resistance was observed for its phenylpyrrole partner fludioxonil. Until now, cases of resistance to fludioxonil in $B$. cinerea were restricted in strawberry fields in Germany and the United States and vineyards in Germany, mostly associated with overexpression of efflux transporters that confer low or moderate levels of nonspecific resistance to most groups of botryticides $(8,20,26,30)$. In contrast to the absence of resistance to fludioxonil, the presence of $B$. cinerea strains with resistance to the hydroxyanilide fenhexamid is confirmed for the first time in strawberry fields in Greece. Resistance to fenhexamid in pathogen strains in Greece had previously been reported only in lettuce fields (6). However, resistance to fenhexamid is a common trait in fungal populations in Germany (41) and the United States (17). The absence of resistance to fenhexamid in fungal populations from tomato or the very low frequency of resistance observed in strawberry isolates from the region of Pieria is probably associated with the relatively low number of fenhexamid applications. Growers in Greece do not rely on fenhexamid application because it has a restricted activity spectrum and they prefer to apply other compounds with a broader activity spectrum such as SDHIs, QoIs, and APs.

Investigation of the gray mold pathogen population structure in terms of $B$. cinerea sensu stricto and $B$. cinerea group $S$ revealed the presence of group $S$ in both strawberry fields and tomato greenhouses, although with different frequencies. B. cinerea group $\mathrm{S}$ isolates were identified for the first time in strawberry fields of Germany at frequencies of 35 to $100 \%$ of the sampled isolates (23). Despite their predominance in German strawberry fields, they were only rarely found in vineyard populations (23). The presence of group $\mathrm{S}$ isolates was also confirmed in fungal populations from vineyards in N. Zealand (18) and blackberry in the United States (26). In contrast to the frequencies observed in German strawberry fields, in the current study, we found that $B$. cinerea group $\mathrm{S}$ isolates were present only at low frequencies in strawberry fields. The presence of this novel $B$. cinerea group was also confirmed in the isolates obtained from greenhouse-grown tomato. Interestingly, $B$. cinerea group $\mathrm{S}$ isolates were predominant in all three regions sampled, although with variable frequencies.

Several factors may contribute to the structure of $B$. cinerea populations such as host or organ preference, temporal succession, and sensitivity to fungicides $(14,28)$. The observed predominance of $B$. cinerea group $\mathrm{S}$ in all three regions from which tomato greenhouses were sampled may suggest that this novel clade is better adapted on this host compared with $B$. cinerea sensu stricto. However, further research is required to confirm this hypothesis. The current study provides evidence for the effects of fungicide resistance in shaping the structure of $B$. cinerea populations. We found that $B$. cinerea sensu stricto isolates were more prone to development of resistance to the respiration inhibitors (boscalid and pyraclostrobin) compared with the group $\mathrm{S}$ isolates that were only rarely resistant to these two fungicides. In contrast, for the remaining fungicides tested, it was shown that the ability of $B$. cinerea sensu stricto and $B$. cinerea group $\mathrm{S}$ isolates to develop resistance was variable. Thus, the observed predominance of $B$. cinerea sensu stricto in the strawberry populations is probably related to the high frequency of resistance to boscalid or pyraclostrobin. Differences in the fungicide resistance profile between the two Botrytis groups were also observed by Leroch et al. (23), who reported that group $\mathrm{S}$ isolates were more prone to accumulation of different specific resistances if they carried a specific 3-bp 
deletion in the $m r r 1$ gene associated with the multidrug resistance phenotype MDR1h. The widespread presence of this phenotype within the German strawberry fields and its complete absence in the Greek strawberry fields may explain the differences in frequencies of Botrytis group S among Greek and German strawberry fields. However, despite the ability of $B$. cinerea group $S$ to accumulate of fungicide resistance mutations, it was also observed that, within this group, resistance to boscalid was rare (23). However, it is not excluded that further selection pressure from exposure to SDHIs or QoIs would lead to an increase of $B$. cinerea group $\mathrm{S}$ with resistance to SDHIs.

The observed prevalence of multiple resistances to fungicides within the fungal populations tested represents a major threat for the successful control of gray mold. The restricted availability of new molecules with different modes of action necessitates the implementation of antiresistance strategies aimed at delaying increase in fungicide resistance and maintaining efficacy of available compounds.

\section{Acknowledgments}

This research has been co-financed by the European Union (European Social Fund $[E S F]$ ) and Greek national funds through the Operational Program "Education and Lifelong Learning" of the National Strategic Reference FrameworkResearch Funding Program THALES, project M15380264, entitled "Development of IT and molecular diagnostics tools for improving the sustainability of pesticide based approaches to control agricultural pests of major economic importance in Greece." We thank BASF Hellas S.A. for providing financial support; A. Gatsios, A. Paraskevopoulos, and C. Stefanakis for their aid in field and greenhouse sampling; and P. Kalogeropoulou for technical support in bioassays and DNA extraction procedure.

\section{Literature Cited}

1. Amiri, A., Heath, S. M., and Peres, N.A. 2013. Phenotypic characterization of multifungicide resistance in Botrytis cinerea isolates from strawberry fields in Florida. Plant Dis. 97:393-401.

2. Amiri, A., Heath, S. M., and Peres, N. A. 2014. Amiri, A., Heath, S. M., and Peres, N. A. 2014. Resistance to fluopyram, fluxapyroxad, and penthiopyrad in Botrytis cinerea from strawberry. Plant Dis. 98:532-539.

3. Bardas, G. A., Myresiotis, C. K., and Karaoglanidis, G. S. 2008. Stability and fitness of anilinopyrimidine-resistant strains of Botrytis cinerea. Phytopathology 98:443-450.

4. Bardas, G. A., Veloukas, T., Koutita, O., and Karaoglanidis, G. S. 2010. Multiple resistance of Botrytis cinerea from kiwifruit to SDHIs, QoIs and fungicides of other chemical groups. Pest Manage. Sci. 66:967-973.

5. Beever, R. E., and Weeds, P. L. 2007. Taxonomy and genetic variation of Botrytis and Botryotinia. Pages 29-52 in: Botrytis: Biology, Pathology and Control. Y. Elad, B. Williamson, P. Tudzynski, and N. Delen, eds. Springer, Dordrecht, The Netherlands.

6. Chatzidimopoulos, M., Papaevagellou, D., and Pappas, A. C. 2013. Detection and characterization of fungicide resistant phenotypes of Botrytis cinerea in lettuce crops in Greece. Eur. J. Plant Pathol. 137:363-376.

7. Elad, Y., Williamson, B., Tudzynski, P., and Delen, N. 2007. Botrytis spp. and diseases they cause in agricultural ecosystems-An introduction. Pages 1-8 in: Botrytis: Biology, Pathology and Control. Y. Elad, B. Williamson, P. Tudzynski, and N. Delen, eds. Springer, Dordrecht, The Netherlands.

8. Fernandez-Ortuno, D., Bryson, P. K., Grabke, A., and Schnabel, G. 2013. First report of fludioxonil resistance in Botrytis cinerea from strawberry field in Virginia. Plant Dis. 97:848.

9. Fernandez-Ortuno, D., Chen, F., and Schnabel, G. 2012. Resistance to pyraclostrobin and boscalid in Botrytis cinerea isolates from strawberry in the Carolinas. Plant Dis. 96:1198-1203.

10. Fillinger, S., Leroux, P., Auclair, C., Barreau, C., Al Hajj, C., and Debieu, D. 2008. Genetic analysis of fenhexamid-resistant field isolates of the phytopathogenic fungus Botrytis cinerea. Antimicrob. Agents Chemother. 52:3933-3940

11. Fournier, E., and Giraud, T. 2008. Sympatric genetic differentiation of a generalist pathogenic fungus, Botrytis cinerea, on two different host plants, grapevine and bramble. J. Evol. Biol. 21:122-132.

12. Fournier, E., Giraud, T., and Brygoo, Y. 2005. Partition of the Botrytis cinerea complex in France using multiple gene genealogies. Mycologia 97:1251-1267.

13. Fungicide Resistance Action Committee (FRAC). 2013. SDHI Working Group. Minutes of 2012 SDHI meeting, recommendations for 2013 Online publication. www.frac.info

14. Giraud, T., Fortini, D., Levis, C., Lamarque, C., Leroux, P., LoBuglio, K., and Brygoo, Y. 1999. Two sibling species of the Botrytis cinerea complex, transposa and vacuma are found in sympatry on numerous host plants. Phytopathology 89:967-973.

15. Giraud, T., Fortini, D., Levis, C., Leroux, P., and Brygoo, Y. 1997. RFLP markers show genetic recombination in Botryotinia fuckeliana (Botrytis ci- nerea) and transposable elements reveal two sympatric species. Mol. Biol. Evol. 14:1177-1185.

16. Grabke, A., Fernandez-Ortuno, D., Amiri, A., Li, X., Peres, N. A., Smithm P., and Schnabel, G. 2014. Characterization of iprodione resistance in Botrytis cinerea from strawberry and blackberry. Phytopathology 104:396402.

17. Grabke, A., Fernandez-Ortuno, D., and Schnabel, G. 2013. Fenhexamid resistance in Botrytis cinerea from strawberry fields in the Carolinas is associated with four target gene mutations. Plant Dis. 97:271-276.

18. Johnston, P. R., Hoksbergen, K., Park, D., and Beever, R. E. 2014. Genetic diversity of Botrytis in New Zealand vineyards and the significance of its seasonal and regional variation. Plant Pathol. 63:888-898. doi:10.1111/ppa.12143

19. Kim, Y. K., and Xiao, C. L. 2010. Resistance to pyraclostrobin and boscalid in populations of Botrytis cinerea from stored apples in Washington State. Plant Dis. 94:604-612.

20. Kretschmer, M., Leroch, M., Mosbach, A., Walker, A.-S., Filinger, S., Mernke, D., Schoonbeek, H., Pradier, J., Leroux, P., DeWaard, M., and Hahn, M. 2009. Fungicide-driven evolution and molecular basis of multidrug resistance in field populations of the grey mould fungus Botrytis cinerea. PLoS Pathog. 5:e1000696.

21. Laleve, A., Gamet, S., Walker, A.-S., Debieu, D., Toquin, V., and Fillinger, S. 2014. Site-directed mutagenesis of the P225, N230 and $\mathrm{H} 272$ residues of succinate dehydrogenase subunit B from Botrytis cinerea highlights different roles in enzyme activity and inhibitor binding. Environ. Microbiol 16:2253-2266. doi:10.1111/1462-2920.12282

22. Leroch, M., Kretchmer, M., and Hahn, M. 2011. Fungicide resistance phenotypes of Botrytis cinerea isolates from commercial vineyards in South West Germany. J. Phytopathol. 159:63-65.

23. Leroch, M., Plesken, C., Weber, R. W. S., Kauff, F., Scalliet, G., and Hahn, M. 2013. Gray mould populations in German strawberry fields are resistant to multiple fungicides and dominated by a novel clade closely related to $\mathrm{Bo}$ trytis cinerea. Appl. Environ. Microbiol. 79:159-167.

24. Leroux P, 2007. Chemical control of Botrytis and its resistance to chemical fungicides. Pages 195-222 in: Botrytis: Biology, Pathology and Control. Y. Elad, B. Williamson, P. Tudzynski, and N. Delen, eds. Springer, Dordrecht, The Netherlands.

25. Leroux, P., Gredt, M., Leroch, M., and Walker, A.-S. 2010. Exploring mechanisms of resistance to respiratory inhibitors in field strains of Botrytis cinerea, the causal agent of gray mold. Appl. Environ. Microbiol. 76:66156630

26. Li, X., Fernández-Ortuño, D., Grabke, A., and Schnabel, G. 2014. Resistance to fludioxonil in Botrytis cinerea isolates from blackberry and strawberry. Phytopathology 104:724-732.

27. Ma, Z. H., Yan, L. Y., Luo, Y., and Michailides, T. J. 2007. Sequence variation in the two component histidine kinase gene of Botrytis cinerea associated with resistance to dicarboximide fungicides. Pestic. Biochem. Physiol. 88:300-306.

28. Martinez, F., Dubos, B., and Fermaud, M. 2005. The role of saprotrophy and virulence in the population dynamics of Botrytis cinerea in vineyards. Phytopathology 95:692-700.

29. Mehta, C., and Patel, R. 1996. SPSS Exact Tests 7.0 for Windows. SPSS Inc., Chicago.

30. Mernke, D., Dahm, S., Walker, A.S., Laleve, A., Fillinger, S., Leroch, M., and Hahn M. 2011. Two promoter rearrangements in a drug efflux transporter gene are responsible for the appearance and spread of multidrug resistance phenotype MDR2 in Botrytis cinerea isolates in French and German vineyards. Phytopathology 101:1176-1183.

31. Myresiotis, C. K., Karaoglanidis, G. S., and Tzavella-Klonari, K. 2007. Monitoring for resistance of Botrytis cinerea isolates from vegetable crops to anilinopyrimidine, phenylpyrrole, hydroxyanilide, benzimidazole and dicarboximide fungicides. Plant Dis. 91:407-413.

32. Raposo, R., Delcan, J., Gomez, V., and Melgarejo, P. 1996. Distribution and fitness of isolates of Botrytis cinerea with multiple fungicide resistance in Spanish greenhouses. Plant Pathol. 45:497-505.

33. Samuel, S., Papayiannis, L. C., Leroch, M., Veloukas, T., Hahn, M., and Karaoglanidis, G. S. 2011. Evaluation of the incidence of the G143A mutation and $c y t b$ intron presence in the cytochrome $b c 1$ gene conferring QoI resistance in Botrytis cinerea populations from several hosts. Pest Manage. Sci. 67:1029-1036.

34. Sierotzki, H., and Scalliet, G. 2013. A review of current knowledge of resistance aspects for the next-generation succinate dehydrogenase inhibitor fungicides. Phytopathology 103:880-887.

35. Stammler, G., Brix, H. D., Nave, B., Gold, R., and Schoefl, U. 2008. Studies on the biological performance of boscalid and its mode of action. Pages 45-51, in: Modern Fungicides and Antifungal Compounds. V. H. W. Dehne, H. B. Deising, U. Gisi, P. E. Russell, and H. Lyr, eds. Deutsche Phytomedizinische Gesellschaft, Braunschweig, Germany.

36. Veloukas, T., Kalogeropoulou, P., Markoglou, A. N., and Karaoglanidis, G. S. 2014. Fitness and competitive ability of Botrytis cinerea field-isolates with dual resistance to SDHI and QoI fungicides, associated with several $s d h \mathrm{~B}$ and the $c y t \mathrm{~b}$ G143A mutations. Phytopathology 104:347-356.

37. Veloukas, T., Leroch, M., Hahn, M., and Karaoglanidis, G. S. 2011. Detection and molecular characterization of boscalid-resistant Botrytis cinerea 
isolates from strawberry. Plant Dis. 95:1302-1307.

38. Veloukas, T., Markoglou, A. N., and Karaoglanidis, G. S. 2013. Differential effect of $S d h B$ gene mutations on the sensitivity to SDHI fungicides in Botrytis cinerea. Plant Dis. 97:118-122.

39. Walker, A., Gautier, A., Confais, J., Martinho, D., Viaud, M., Le Pêcheur, P., Dupont, J., and Fournier, E. 2011. Botrytis pseudocinerea, a new cryptic species causing gray mould in French vineyards in sympatry with Botrytis cinerea. Phytopathology 101:1433-1445.

40. Walker, A.-S., Micoud, A., Remuson, F., Grosman, J., Gredt, M., and Leroux, P. 2013. French vineyards provide information that opens ways for effective resistance management of Botrytis cinerea (grey mould). Pest Manage. Sci. 69:667-678.

41. Weber, R. W. S. 2011. Resistance of Botrytis cinerea to multiple fungicides in Northern German small-fruit production. Plant Dis. 95:1263-1269.

42. Yin, Y. N., Kim, Y. K., and Xiao, C. L. 2011. Molecular characterization of boscalid resistance in field isolates of Botrytis cinerea from apple. Phytopathology 101:986-995.

43. Yourman, L. F., Jeffers, S. N., and Dean, R. A. 2000. Genetic analysis of isolates of Botrytis cinerea sensitive and resistant to benzimidazole and dicarboximide fungicides. Phytopathology 90:851-859. 